\title{
Beyond Rights: The Ethical Challenge ${ }^{1}$
}

\section{Vangie Bergum}

University of Alberta

If we look into prevailing moral discourse, at the level of either everyday moral life or of ethical theory, a number of common themes can be discovered. There is, for instance, a great deal of talk about rights: of fetuses, infants, children, the young, the elderly, and women; of blacks, Hispanics, and other minorities; of those in need of organ transplantations and those with organs to donate; and on and on. (Zaner, 1988, pp. 285-286)

The rhetoric of rights, rights as justified claims, validated by moral principles and rules is often expressed as the right to health care (in birth, in life, and in death), to equal opportunity, equal access, unlimited medical care, to autonomous, independent, informed decision making, to choice about whether to accept certain treatment, and to legalized living wills. The passions experienced by activists in the demand for these rights can be readily seen in heated abortion and euthanasia debates.

If we look on the surface of things, the emphasis on rights has served us well, as it has led to attention to self-determination by patients, to a critique of medical paternalism, to respect for individual wants and desires, to requirement for informed consent, and the education of patients. However, if we look more deeply, we might see that an ethic or moral theory based on rights leads to a flattening and narrowing of our human life. ${ }^{2}$

Led by Gilligan (1982), scholars such as Held (1988) and Carse (1991) argue that there is need for more attention to relationship and care as the focus of ethical commitments, especially in situations of illness. Yet, although voices calling for an ethic of care seem to be heard more loudly and more frequently, there also seems to be a moral floundering. What kind of relationship is important in the clinical situation? What makes for right and good health care relation? What must the professional be and $d o ?^{3}$ What are patients' responsibility in the relationship? The intent of this article is to explore the nature of the ethical encounter in health care and to show the limitations of current bioethical thinking. I aim to reconstruct a vision of ethical commitment as one that holds central the relational encounter between professional and patient. 


\section{The Need for Relation}

In a recent book, Strangers at the Bedside, Rothman (1991) provides an historical analysis of how over the past couple of decades medical decision making has moved away from the domain of the physician and patient to a situation that includes ethics committees, lawyers, rights advocates, family members, and others. The result of this move is that patients may well continue to experience medicine as modern and powerful, as well as "a more or less efficient action between strangers" (p. 262). Modern hospital images of care for the dying may show a room with a bed surrounded by numerous pieces of technology. Only by careful scrutiny may one see the thin body of a person lying on that bed. No one is in the room with the patient. One can imagine the "company of strangers" meeting down the hall to discuss whether to discontinue treatment, to review whether the patient had met the criteria of brain death, or to search for evidence of the patient's wishes.

Recall the Gulf War. It was fought to uphold a country's right to self-determination and, in the words of the American president, to uphold the rights to freedom, democracy, and justice. And in order to maintain public support for such a war, it was bought to us through television and radio as a war without people. We saw statistics, we saw planes and fireworks, we saw damaged, empty buildings. We did not see people. We did not see the dead and wounded children, women, men, and soldiers. Yet thousands of civilians and more than 125,000 soldiers died. Of the casualties three out of every seven have been and will be children (Noorani, 1991, pp. 5-6). Operation Desert Storm renames the act of injuring and killing people into strategies and calculations (operations) and impersonal and irrational nature (desert storm). War renders people as objects to be counted in statistics, but not counted as unique individuals who matter. Counting people as statistics removes the possibility of relations with them or responsibility for them as individual people.

Think of the dilemma of adopted children. Headlines in a local paper read The Dream of Meeting Birth Parents Can Become a Nightmare. The article discusses the troubled unions that sometimes result when adopted children meet birth parents. Parent Finders, a nonprofit search group that helps adoptees, birth parents, and siblings find their blood relations, has been criticized for causing crises in relationships between adoptees and adoptive parents. Yet "children who seek out birth parents say they need to know where they came from, even if it ends in disaster ... There is always a void there ... No matter how great your adoptive parents are, you don't have an identity" (Retson, 1991, p. E2). Adopted children seem to need to know themselves as someone with roots, to know, and be known by their original genetic connections, their ethnic background. They long for someone who looks like them. ${ }^{4}$ 
However caring and loving their adoptive parents are, some children search for the distinctive, particular "face" of the birth mother that has meaning for increased self-understanding. Children may come to a better sense of themselves through experiencing renewed relation with their birth mother and/or their genetic father.

These very different experiences point to a same truth: the need for face-fulness, uniqueness, integrity of self, that is fostered through relation with others in some situations, particular, unique others. This uniqueness of personhood, of children, of women, and of men may be in danger of getting lost in the rhetoric of rights, where the body is objectified and a person becomes a statistic. The recent emphasis on care and relationship must also be heedful of the importance of the unique integrity of persons involved in such relations. The adopted child, the war dead, and the dying person remind us of the ethical relational claim to which we need to respond.

\section{The Ethics of Relationship}

Current ethical decision making (based on contract theory, on secularbased theory of human rights, and on liberal theories of justice) is used in ethical situations by nurses, physicians, other health care professionals, hospital ethics committees, and the courts. Ethical theories of justice, derived from the moral theories of Kant, Rawls, Mills, and others, have led to the use of bioethical principles of beneficence, nonmaleficence, autonomy, and justice in medical decision making. Theories of justice, as exemplified by the contract relation between equal partners of the business world, are based on the experience of separateness (individuation, individualism, autonomy). Such theories are now being questioned because they are thought to be limited in providing directives to actual health care situations (Clouser \& Gert, 1990; R.L. Holmes, 1990). They are missing an emphasis on care and relationship (Ruddick, 1989). They are ignoring the interests of the family (Hardwig, 1990). And they fail to meet the needs of nursing, family medicine, or clinical medicine (Fry, 1989; Christie \& Hoffmaster, 1986; Zaner, 1988). The theories of justice, which focus on rights as the "first" virtues of social institutions, are being questioned (Baier, 1987). Gilligan (1983) and others have begun to challenge the emphasis on legalistic theories of justice based on concepts of rights and fairness in favor of an emphasis on theories of moral development based on connection and care. What is needed, says Gilligan, is a morality and subsequent ethic that is "fundamentally dialectical in the sense of containing an ongoing tension between justice and care ... aspiring always to the ideal of a world more caring and more just" (pp. 33,47 ). These scholars are proposing that theories of care are relational and based on the experience of attachment and separation between humans. Theories that sponsor care and relationship as primary vir- 
tues of social ideals and institutions would have two dimensions: "one aimed at achieving satisfying community with others, the other aiming at autonomy or equality of power" (Baier, 1987, p. 44).

Nurse ethicists are also responding to this concern about relationship and understanding of patients' experience of illness. The "care" literature is swelling and there is much discussion about the justice-care dichotomy. Nurses question whether nursing should be based on the knowledge gained through science (a world completely knowable if just the right tools are used; a world rendered the same for everyone; and a world that is uniform, replicable, and predictable, Gadow, 1990; C. Holmes, 1990). These scholars suggest that other knowledge is needed, based on the assumptions that the world we live in (a world that wraps itself around us) is knowable only to the extent that we share experiences with each other. They emphasize the need to understand and be committed to listening to individual patient's stories or life narratives about their journey through illness. Such ethical thinking "may lie in the insistence on an appreciation of the complexity of the moral situation as it is revealed in consideration of the contextual particulars. As this complexity is experienced, it becomes less certain that rules and principles can provide adequate solutions to the dilemma" (Cooper, 1990, p. 215).

The justice tradition in ethics and the focus on individual rights, autonomous choice, and contractual relationships (focus on right action) serves the scientific tradition well, with its emphasis on abstraction and objectification. The care tradition in ethics focusing on the need to take seriously interconnectedness and relationship is more in concert with ambiguous and idiosyncratic events of actual life experience. The call for relationship, a call for attention to embodied empathic relation, can only be experienced between people-based on respect for the patient and his or her experience of illness-attempting to understand what the patient is going through. The challenge for bioethics, for a stronger version of both justice and care, is an ethic of encounter where there is the need for One (nurse, doctor) to respond to the Other (patient). Lippitz (1990 $)^{5}$ describes the ethical encounter as an "obligation brought about by the Other, who acts as my master (maitre). He or she enables me to do what I am not able to do myself: to discover myself as an $I$ in my responsibility for the Other, to step out of the maelstrom of my own self-referential, economic existence" (p. 59). The ethical encounter arises only because the other exists as Other who elicits response. Rights-based ethical principles obliterate the difference between self and other, making us all objects, identical others, a world without selves, just others. Everyone is a stranger. In contrast, an ethic of love or respect discovered in each relationship is a response to the Other, the unique stranger: 
who is in need of everything that is necessary for a human life? By addressing myself to another I practice this responsibility, be it reluctantly or not. A total refusal of it would express itself through murder. Total acceptance would coincide with perfect love. (Peperzak, 1989, p. 17)

Ethical thinking in bioethics needs a new foundation with bricks formed by our understandings of the need for rights held together by our recognition of the need for care and relationship. Ethics built on this foundation moves past the rhetoric of rights (and its rational discourse) to a strong version of relationship (with its support of the moral relevance of emotion) toward a moral sense of love and respect in which one is caught by responsibility for the Other.

\section{Experience of Illness and Healing}

When we get a cold or the flu, we usually mobilize our defenses to heal ourselves: go to bed, take plenty of fluids, extra vitamin C, and perhaps an aspirin. We are not so good at healing cancer, nephrosis, or heart attacks, so we call for help. The nature of nursing and medicine is to assist individuals to heal themselves, the meaning of which may be different for each person. Illness and healing are grounded in the experience of the lived body (as differentiated from the body as an object). In health "we see ourselves identified with our bodies, facing the world and acting on it in essential unity. In illness the body is interposed between us and reality ... the body stands opposite to the self. Instead of serving us, we must serve it" (Pellegrino \& Thomasma, 1981 , pp. 207-208). With illness the objective body is brought into focus, resulting in a dualism of self and body where the interest of the body often gets revered to the extent that there is a forgetfulness of patient as a self. Yet while illness focuses attention (of patient and professional) on the body as object, the patient experiences self and body subjectively as vulnerability. In illness, as in health, "I am my body." But in illness (and in aging) the body is experienced as untrustworthy, causing feelings of vulnerability.

Relief of vulnerability (is this what is meant by healing?) experienced by the patient is not under the control of the nurse or doctor. The professional must rather enter into a relationship with the patient, to ensure that right and good action is taken in respect to the needs of a particular patient so that relief of vulnerability may be experienced by the patient. Right or good healing action is not a commodity to be bought and sold or a product that can be measured like the action of a mechanic on a car, but rather in interaction of the professional and patient. Right and good healing action occurs in interaction between doctor or nurse and patient, and in commitment to "engagement with people in living through, negotiating a passage through, the vulnerability of sickness" (Gadow 1990, p. 14). "Living through" means that the professional maintains ability to reflect on both the objective 
information (for example, laboratory results) and the experience of the patient, in order to assist the patient to make sense of his or her own situation.

\section{Responsibility}

In the professions of nursing and medicine, like teaching and law, a person comes to the professional in need, in vulnerability. The health professional, by the very act of entering into a relationship with a patient who seeks healing, makes an "act of profession."

In the presence of a patient in the peculiar state of vulnerable humanity that is illness, the health professional makes a "profession." He "declares aloud" that he has special knowledge and skills, that he can heal, or help, and that he will do so in the patient's interest, not his own. (Pellegrino \& Thomasma, 1981, p. 209)

The encounter between professional and patient cannot be a relationship between "strangers at the bedside" but an encounter that brings into focus the particular unique otherness of patient and professional, a relation that brings strangers together. The professional comes with scientific competence as well as with a commitment to explore what is worthwhile for this patient through knowledge of the uniqueness of the patient (respect for autonomy, values, confidentiality, etc). The patient comes in trust because of the profession of commitment. Such a relationship is not governed by the technological or instrumental reasoning that presently dominates health care thinking, but one where technology serves our humanity, assisting us to strengthen our rapport with each other (Taylor, 1991). Such a relationship is not contractual as in a simple contract between equals where each party negotiates from a position of self interest. The encounter between professional and patient is such that one party, the professional, is not free to avoid entering, that is, by the very nature of the act of profession the nurse or doctor has stated a readiness to be "caught by the claim of the Other." Because of the increasing numbers of strangers that now surround the bed, to reconstruct bioethics toward a focus on relationship of nurse-patient or doctor-patient as an embodied, empathic responsiveness is imperative. Such an ethical responsiveness occurs as we come face to face with our patients, and in so doing we come face to face with ourselves.

\section{A Bioethics of Otherness}

The foundation of bioethics that I propose departs from the encounter. Interaction between people in itself can be seen as relief of vulnerability, which may be or lead to patient healing. In friendship personal vulnerability vacillates between friends, sometimes one friend expressing vulnerability and at other times the other friend. In illness, vulnerability is primarily expressed by the patient who comes for help, but the professional who responds must also recognize and acknowl- 
edge his or her own vulnerability. Engagement of both patient and professional (the nurse) makes the ethical relation possible, makes sharing of vulnerability possible, and means that "nurses must be re-embodied, must experience their bodies as part of their own subjectivity rather than as unfeeling instruments" (Gadow, 1989, p. 540). Nurses have learned to become disembodied in an effort to avoid suffering patient's pain. Only through "reinhabiting the body does it become possible [for the nurse] to experience the patient's body as a subjective being rather than a mere thing" (p. 540), and thus acknowledge and experience patient's pain. Only through embodiment, and acknowledging his or her own vulnerability, can a nurse become involved in relation with patients that relieves vulnerability, both in relieving the suffering of the patient and relieving the suffering that the nurse may feel. Sacks (1990) describes the ethical encounter for medicine as one in which the professional becomes a fellow traveler, a fellow explorer, continually moving

with his patients, discovering with them the vivid, exact, and figurative language that will reach out towards the incommunicable. Together they must create languages that bridge the gulf between the physician [nurse] and patient, the gulf which separates one man from another. (pp. 225-226)

To be a fellow traveler, instead of seeing the journey as planned on a map the nurse must travel with the patient as lived along the bumpy road through illness together taking the turns and valleys, together viewing the scenery, together deciding on other companions, and together choosing where to go-perhaps even sharing the job of driver. Such a journey and its search for common language blurs the distinction of separate individuals - one the choicemaker, the other choiceless.

The vision of separate, choicemaking individual is a result of the relatively recent emphasis on abstract, universal, scientific knowledge.

The success of scientific medicine during the past half century has prompted physicians to place intense normative value on conceiving themselves as rigidly separate from their external environment, including their patients. This separate, rationally manipulating self-depiction among physicians finds its precise counter part in the notion that patients should be viewed as separate, rationally manipulating individuals. (Burt, 1979, p. 101).

The ethical encounter in health care should introduce doubt in the expectation that there are distinctive personal boundaries when one is in an empathic ethical relation. In such a relation boundaries tend to become diffuse and flexible. In relations between nurse and patient and doctor and patient where there is effort to share the experience of illness confusion may occur as to who is the decision maker. In fact, for many people decisions made in daily life are their own but also they are 
cognizant of whether that decision is good for others in their life. Sharing experiences, sharing feelings and thoughts, using imagination to understand another's pain leads to a relation that blurs the sharp distinction between professionals and patients so important to the justice framework, which need not mean one loses the sense of self nor the opportunity for self-determination. Rather, in spite of the confusion, through honest effort to keep conversation open ${ }^{7}$ each may come to experience self more clearly.

Like the pedagogical relation, the ethical encounter in health care is not merely a means to an end but finds its meaning in the relation itself. Like the pedagogical relation, the ethical encounter of nursing requires a relation that is personal (it is a form of interaction between two persons that cannot be managed or trained, nor reduced to any other human interaction); it is intentional (this means that it is a type of interaction that recognizes the Other as he or she is and may become); and it is oriented (requiring that one be able to interpret and understand the present situation and experiences and to anticipate moments when the patient is ready to increasingly participate in selfdetermining choices, van Manen, 1991). Such a relation uses forms of knowledge that are not abstract but rather immediate, local, intuitive, emotive, informal, and embodied. Subjectively experienced, interaction between patient and professional acknowledges the vulnerability of both and holds onto what it means to be human and to remain human in the face of unimaginable adversities and threats.

The ethical encounter, a nurturant relation visible in that of mother and child (or mother and fetus), is a relation that moves and changes (Bergum, 1989, pp. 38-39), like dance partners sensitive to the movement and rhythm of the other. "Every disease is a musical problem. Every cure is a musical solution," says Sacks (1990), who quoted a patient:

When you walk with me I feel in myself your power of walking. I partake of the power and freedom you have. I share your walking powers, your perceptions, your feelings, your existence. Without even knowing it you make me a great gift. (p. 282)

The debilitating isolation of illness is eased by the contactual (essentially musical) relation making movement, the journey through illness, possible.

Like any other journey, the journey through illness, a subjectively shared relation between professional and patient, leads homeward to recovered health, to living with disability, or to death, which for some is seen as a final home and for others as an end point resisted to the last breath. For someone who is ill, to be homeward bound may be as Sacks (1990) describes his Parkinsonian patients who "come to re-feel the grounds of their being, to re-root themselves in the ground of reality, to 
return to the first-ground, the earth-ground, from which, in their sickness, they had so long departed" (p. 275). Home, more than any other notion perhaps, has personal meanings different for each of us and may in the end be that place of self-acceptance, comfort, or love.

The significance of this concern for the ethic of encounter in which love is possible comes at a time in our history where words like individualism, autonomy, human rights, justice, and personhood have become the grounding of ethical/moral stance. There exists a current emphasis on personal autonomy, on individual rights (for example, maternal versus fetal), on children as commodities, and on women as vessels, on bodies as parts (livers, kidneys, lungs, fetal tissue), on life defined in terms of brain-death criteria, and on health care bound by technological or instrumental reasoning. There also exists the danger of losing the capacity to care deeply for each other-as people who are dependent yet independent, autonomous yet connected to others, sharing yet coming to personal decisions, responsible for others yet anticipating rights for oneself.

Notes

1. I wish to thank Joop Berding and Sally Gadow for reading this paper and offering insights. Many of the ideas have been stimulated by a weekly discussion group with Sally Gadow, Carole Schroeder, and Marjorie McIntyre at the University of Colorado during 1991-1992.

2. See Taylor (1991) for his thesis that modernity's self-interested focus and the primacy of technological or instrumental reasoning (with its search for control and domination of life and death) leads to a fragmentation of community life and a feeling of general malaise or indifference by many people.

3. In this article the professional refers mainly to the nurse and the doctor but may well include other health care professionals such as dentists, psychologists, and other therapists.

4. It is thought by some that this emphasis on genetic connection is culturally constructed to provide for ownership of the child. Yet it may be possible that the "tie that binds" is something remembered in the body as suggested by the words of a young boy to his mother when he sat on her lap, "You know this is my home."

5. Lippitz (1990) bases his work on the French philosopher Levinas' (1979) meaning of ethical responsibility as experienced by the ethical event.

6. Of course, it is possible that the patient does not want to be in this kind of relation with the professional, and it is equally possible that the professional, because of personal abilities and beliefs, is not capable of entering such a relation with every patient. However, the professional is committed by the act of declaration of being a nurse or doctor to consider relational interaction of ethical importance.

7. See Gadow (1989) for her discussion of silent patients. Silent patients, generally labeled incompetent, are those seen as choiceless-needing evidence of prior choice through living wills, or needing someone, a guardian, to make decisions on their behalf. Gadow discusses another possibility, that of advocacy, in which the nurse's subjective, embodied involvement and "personal devotion to the most mundane intimacies of physical care" allows the nurse to "slowly sense where the boundary lies between harm and benefit in the patient's world." Through embodiment the nurse relates with patient's bodies as feeling subjects rather than objects and makes possible "the nurse speaking with the patient's voice" (pp. 540-541). 


\section{References}

Baier, A. (1987). The need for more than justice. Canadian Journal of Philosophy, Supplementary Volume 13, 41-55.

Bergum, V. (1989). Woman to mother. A transformation. South Hadley, MA: Bergin \& Garvey.

Burt, R. (1979). Taking care of strangers. The rule of law in doctor-patient relations. New York: Free Press.

Carse, A.L. (1991). The "voice of care": Implications for bioethical education. Journal of Medicine and Philosophy, 16, 5-28.

Christie, R.J., \& Hoffmaster, C.B. (1986). Ethical issues in family medicine. New York: Oxford University Press.

Clouser, K.D., \& Gert, B. (1990). A critique of principlism. Journal of Medicine and Philosophy, 15, 219-236.

Cooper, M.C. (1990). Reconceptualizing nursing ethics. Scholarly Inquiry for Nursing Practice, 4, 209-221.

Fry, S.T. (1989). The role of caring in a theory of nursing ethics. Hypatia, 4(2), 88-103.

Gadow, S. (1989). Clinical subjectivity: Advocacy with the silent patients. Nursing Clinics of North America, 24(12), 535-554.

Gadow, S. (1990). Beyond dualism: The dialectic of caring and knowing. Unpublished paper presented at the Care-Justice: Education for Ethical Nursing Practice, University of Minnesota.

Gilligan, C. (1982). In a different voice. Cambridge, MA: Harvard University Press.

Gilligan, C. (1983). Do the social sciences have an adequate theory of moral development? In N. Haan, R. Bellah, P. Rabinow, \& W. Sullivan (Eds.), Social science as moral inquiry (pp. 33-51). New York: Columbia University Press.

Hardwig, J. (1990). What about the family? Hastings Center Report, 20(2), 5-10.

Held, V. (1988). Non-contractual society: A feminist view. Canadian Journal of Philosophy, 13, 111-137.

Holmes, C. (1990). Alternatives to natural science foundations for nursing. International Journal of Nursing Studies, 27(3), 187-198.

Holmes, R.L. (1990). The limited relevance of analytical ethics to the problems of bioethics. Journal of Medicine and Philosophy, 15, 143-159.

Levinas, E. (1979). Totality and infinity. Boston: Nijhoff.

Lippitz, W. (1990). Ethics as limits of pedagogical reflection. Phenomenology + Pedagogy, 8, 49-60.

Noorani, A. (1991). Peace mobility, like Gulf War, still on. Canadian Peace Report, 3(1), 5-6.

Pellegrino, E.D., \& Thomasma, D.C. (1981). A philosophical basis of medical practice: A philosophy and ethic of healing professions. New York: Oxford University Press.

Peperzak, A. (1989). From intentionality to responsibility: On Levinas's philosophy of language. In A.B. Dallery \& Charles E. Scott (Eds.), The question of the other (pp. 3-21). New York: State University of New York Press.

Retson, D. (1991). The dream of meeting birth parents can become a nightmare. Edmonton Journal, July 14.

Rothman, D. (1991). Strangers at the bedside. A history of how law and bioethics transformed medical decision-making. New York: Basic Books.

Ruddick, S. (1989). Maternal thinking. Toward a politics of peace. New York: Ballantine Books.

Sacks, O. (1990). Awakenings. New York: Harper Perennial.

Taylor, C. (1991). The malaise of modernity. Concord, ON: House of Anansi Press. van Manen, M. (1991). The vitality of the pedagogical relation. In B. Levering, S.

Miedema, S. Smith, \& M. van Manen (Eds.), Reflections on pedagogy and method (vol. 2). Montfoort: Huriah Heep.

Zaner, R. (1988). Ethics and the clinical encounter. Englewood Cliffs, NJ: Prentice Hall. 